\title{
COMPORTAMENTO ESTRATÉGICO ORGANIZACIONAL E A PRÁTICA DE GERENCIAMENTO DE RESULTADOS NAS EMPRESAS BRASILEIRAS
}

\section{RESUMO}

O comportamento estratégico organizacional interfere na competitividade, no desempenho e na expansão empresarial, ao passo que a discricionariedade dos gestores sobre as escolhas contábeis pode ser prejudicial para a reputação organizacional no mercado de capitais, podendo atenuar os conflitos de agência. A inquietação da pesquisa relaciona-se à possibilidade de que o comportamento estratégico organizacional pode ser transformado em atitudes oportunistas da gestão que contemplam similaridades estratégias de agressividade, criatividade, flexibilidade e proatividade. O objetivo do estudo foi verificar o efeito dos diferentes comportamentos estratégicos organizacionais sobre o comportamento oportunistas dos gestores em práticas de gerenciamento de resultados mediante escolhas contábeis. A amostra da pesquisa foi constituída de 78 empresas dos segmentos de bens industriais, consumo não-cíclico e materiais básicos. Os resultados indicam que as firmas com comportamento estratégico de agressividade e criatividade, pelas características estratégicas prospectora e/ou analisadora, tendem a apresentar comportamentos similares sobre as escolhas contábeis oportunistas pelo uso da discricionariedade, realizando práticas de gerenciamento de resultados com objetivo de apresentar maiores lucros. Os resultados apontam que os diferentes comportamentos estratégicos organizacionais provocam comportamentos oportunistas que se refletem em práticas de gerenciamento de resultados. Os achados sugerem que: a) empresas com estratégias de diferenciação e inovação transferem a agressividade do mercado competitivo para as práticas oportunistas de contabilidade; b) empresas com estratégias de liderança em custo são menos proativas para práticas de gerenciamento de resultados; c) empresas da tipologia prospectora e analisadora, de comportamento agressivo, tendem ao gerenciamento de resultados para melhorar os lucros, por outro lado, aquelas de tipologia defensora apresentam efeito oposto.

Palavras-chave: Estratégias Competitivas; Gerenciamento de Resultados; Tipologias Estratégicas; Empresas Brasileiras.

\section{BEHAVIOR STRATEGIC ORGANIZATIONAL AND RESULTS MANAGEMENT PRACTICE IN} BRAZILIAN

\section{ABSTRACT}

The strategic organizational behavior interferes with competitiveness, performance and business expansion, while the discretion of managers on the financial choices can be detrimental to organizational reputation in the market and could mitigate agency conflicts. Restlessness research relates to the possibility that the organizational strategic behavior can be turned into opportunistic attitudes of management that include similarities aggressive strategies, creativity, flexibility and proactivity. The aim of the study was to investigate the effect of different organizational strategic behavior on the opportunistic behavior of managers in management results through accounting choices practices. The survey sample consisted of 78 companies in the sector of industrial goods, non-cyclical consumption and basic materials. The results indicate that firms with strategic behavior of aggressiveness and creativity, the strategic characteristics prospector and / or analyzer, tend to have similar behavior on opportunistic accounting choices when using discretion, performing results management practices in order to show higher profits. The results show that the different organizational strategic behaviors cause opportunistic behavior that are reflected in earnings management practices. The findings suggest that: a) companies with differentiation and innovation strategies transfer the aggressiveness of the competitive market for opportunistic accounting practices; b) companies with leadership strategies in cost are less proactive in earnings management practices; c) companies prospector type and analyzer, aggressive behavior, tend to earnings management to improve profits, on the other hand, those type of defender have opposite effect.

Keywords: Competitive Strategies; Earnings Management; Strategic typologies; Brazilian Companies. 


\section{COMPORTAMIENTO ESTRATÉGICO GESTIÓN DE ORGANIZACIÓN Y RESULTADOS EN LA PRÁCTICA DE BRASIL}

\section{RESUMEN}

El comportamiento de la organización estratégica interfiere con la competitividad, el rendimiento y la expansión de los negocios, mientras que la discreción de los administradores sobre las decisiones financieras puede ser perjudicial para la reputación de la organización en el mercado y podría mitigar los conflictos de agencia. Inquietud la investigación se refiere a la posibilidad de que el comportamiento estratégico de la organización se puede convertir en actitudes oportunistas de gestión que incluyen similitudes estrategias agresivas, la creatividad, la flexibilidad y proactividad. El objetivo del estudio fue investigar el efecto de diferentes comportamientos estratégicos de la organización sobre el comportamiento oportunista de los administradores en los resultados de gestión a través de prácticas opciones de contabilidad. La muestra de la encuesta constaba de 78 empresas en el sector de bienes industriales, el consumo no cíclico y materiales básicos. Los resultados indican que las empresas con un comportamiento estratégico de la agresividad y la creatividad, las características estratégicas prospector y / o el analizador, tienden a tener un comportamiento similar en las opciones de contabilidad oportunistas cuando se utiliza la discreción, la realización de prácticas de gestión de resultados con el fin de mostrar mayores ganancias . Los resultados muestran que los diferentes comportamientos estratégicos organizacionales causan un comportamiento oportunista que se reflejan en las prácticas de gestión de los ingresos. Los resultados sugieren que: a) las empresas con estrategias de diferenciación e innovación transferir la agresividad del mercado competitivo para las prácticas de contabilidad oportunistas; b) empresas con estrategias de liderazgo en costos son menos proactiva en las prácticas de gestión de los ingresos; c) las empresas prospector tipo y el analizador, el comportamiento agresivo, tienden a la gestión de los ingresos para mejorar las ganancias, por el contrario, ese tipo de defensa tiene un efecto contrario.

Palabras clave: Estrategias Competitivas; Gestión de las Ganancias; Tipologías Estratégicas; Las Empresas Brasileñas.

\footnotetext{
${ }^{1}$ Doutorando em Ciências Contábeis e Administração pela Universidade Regional de Blumenau - FURB. Brasil. Email: cristianbaumagro@gmail.com

${ }^{2}$ Mestre em Ciências Contábeis pela Universidade Regional de Blumenau - FURB. Professor da Universidade Federal da Grande Dourados - UFGD. Brasil. E-mail: thiagobruno.silva@yahoo.com

${ }^{3}$ Doutor em Ciências Contábeis e Administração pela Universidade Regional de Blumenau - FURB. Professor do Programa de Pós-Graduação em Ciências Contábeis da Universidade Regional de Blumenau - FURB. Brasil. E-mail: rklann@furb.br
} 


\section{INTRODUÇÃ̃O}

A estratégia se reflete em ações que determinam o rumo organizacional e direcionam os fatores operacionais e gerenciais. A adequação estratégica visa determinar a vantagem competitiva, por meio de direcionadores da expansão empresarial, satisfação de clientes, competitividade mercadológica, dentre outros fatores (Thompson Jr., Strickland \& Gamble, 2008). Desse modo, a vantagem competitiva está atrelada à adoção de diferentes comportamentos estratégicos organizacionais, em que Miles, Snow, Meyer e Coleman (1978) categorizam como topologias estratégicas.

As tipologias estratégicas delineadas por Pleshko e Nickerson (2008) remetem que as empresas com tipologia prospectora e/ou analisadora possuem propensão para comportamentos estratégicos de agressividade, criatividade, flexibilidade e proatividade. Além disso, o foco relaciona-se à diferenciação de produtos pela constante inovação dos processos e mercado (Slater \& Narver, 1993; AragónSánchez \& Sánchez-Marín, 2005; Olson, Slater \& Hult, 2005; Malone, Chan, Love \& Rayner, 2008). Por outro lado, as organizações com tipologia defensora e/ou reativa possuem menor proatividade e primam pela liderança em custo e na manutenção de mercados específicos com baixa concorrência (Miles et al., 1978).

Miles et al. (1978) argumentam que o defensor e o prospector estão, estrategicamente, em lados opostos, e o analisador utiliza uma mescla estratégica que contempla, com maior ênfase, as características do prospector. Por fim, o reativo atua no mercado de maneira pacífica e se mostra relutante à agressividade e criatividade no combate à concorrência (Miles et al., 1978; Slater \& Narver, 1993; Aragón-Sánchez \& Sánchez-Marín, 2005; Olson et al., 2005; Malone et al., 2008; Pleshko \& Nickerson, 2008).

De acordo com Miles et al. (1978), a classificação do comportamento estratégico tem a finalidade de caracterizar, em função das pressões ambientais, a tomada de decisões das organizações. As tipologias estratégicas são fatores determinantes dos ajustes internos na estrutura, nas relações de trabalho e nos processos gerenciais das organizações. Do mesmo modo, estabelecem as prioridades estratégicas de adequação dos processos de fabricação e sistemas de informação, incluindo as informações oferecidas pela contabilidade (Johnson \& Kaplan, 1987; Shank \& Govindarajan, 1993).

O comportamento estratégico norteia o rumo presente e futuro da organização, mantendo um equilíbrio estrutural para combater a concorrência, implementando ações que modificam os processos internos operacionais e de gestão, que incluem escolhas de contabilidade (Healy \& Palepu, 2012; Andayani \& Warsono, 2013). Do mesmo modo, Bentley, Omer e
Sharp (2013) atribuem que o comportamento estratégico organizacional se materializa quando for disseminado e amplamente aceito em todos os níveis organizacionais, interferindo na complexidade $e$ flexibilidade dos processos e da gestão intraorganizacional.

Nesse aspecto, estratégias de negócio que envolvem a diferenciação e constante inovação devem transferir para os diversos níveis organizacionais tal agressividade competitiva. Por outro lado, empresas com estratégias de liderança em custo e que primam pela manutenção de um único mercado precisam disseminar essa compreensão de competitividade para os demais níveis organizacionais, interferindo em todo o processo operacional e de gestão (Miles et al., 1978; Olson et al., 2005; Malone et al., 2008).

Diante das considerações expostas, a informação contábil pode ser influenciada pela adoção de diferentes tipologias estratégicas. Rodrigues e António (2010) explicam que as estratégias adotadas pelas organizações parecem ser determinadas pela reação dos gestores aos diferentes mecanismos de controle, internos e/ou externos. Segundo Miles et al. (1978), é provável que haja uma associação entre as diferentes tipologias estratégicas e as escolhas contábeis, neste caso, as práticas de gerenciamento de resultados.

Andayani e Warsono (2013) sugerem que os diferentes comportamentos estratégicos disseminam sua compreensão de negócio em escolhas de contabilidade que se tornam compatíveis (Andayani \& Warsono, 2003). De maneira complementar, Bentley et al. (2013) relatam que o comportamento estratégico agressivo provoca reflexo negativo sobre a qualidade da informação contábil. Wu, Gao e Gu (2015) também inferem que as empresas com estratégias de diferenciação e inovação estão propensas a práticas de gerenciamento de resultados.

A inquietação da pesquisa relaciona-se ao fato da possibilidade de que o comportamento estratégico organizacional pode ser transformado em atitudes organizacionais de mesma ênfase, para outras áreas que não estejam relacionadas aos fatores de produção, mas a escolhas administrativas e de gestão que envolvem as práticas de contabilidade, dentro dos limites impostos pela legislação vigente.

Diante das argumentações surge a seguinte problemática de pesquisa: Qual o efeito dos diferentes comportamentos estratégicos organizacionais sobre o comportamento oportunista dos gestores em práticas de gerenciamento de resultados mediante escolhas contábeis? Para tanto, o estudo tem o objetivo de verificar o efeito dos diferentes comportamentos estratégicos organizacionais sobre o comportamento oportunista dos gestores em práticas de gerenciamento de resultados mediante escolhas contábeis.

Estudos sob essa ênfase focalizaram no efeito do comportamento estratégico organizacional sobre as 
práticas de gerenciamento mediante atividades reais (Andayani \& Warsono, 2013; Wu et al., 2015). Desse modo, a presente pesquisa avança ao demonstrar que o comportamento estratégico organizacional pode ser transferido não apenas em ações operacionais (Andayani e Warsono, 2013; Wu et al., 2015), mas também nos demais aspectos organizacionais, com foco nas escolhas contábeis oportunistas.

Este estudo se justifica ao considerar as ponderações teóricas sobre a necessidade de validação e testes das suposições empíricas sobre as estratégias competitivas (Zajac \& Shortell, 1989; Shortell \& Zajac, 1990; Conant, Smart \& Solano-Mendez, 1993). Os autores observaram o fato de que a pesquisa de Miles e Snow foi limitada pelo número de indústrias e gama de capacidades estudadas. As investigações não se dedicaram, de forma sistemática, às possíveis ligações das tipologias estratégicas e seus fatores determinantes subjacentes dos fatores organizacionais.

A contribuição do estudo versa por verificar se a qualidade reportada pelos números contábeis também pode ser influenciada pelas estratégias competitivas de Miles et al., (1978). Torna-se relevante, assim, compreender se as organizações que adotam estratégias similares tendem a incorrer no mesmo comportamento em relação à prática de gerenciamento de resultados. Neste prisma, o estudo contribui em oferecer evidências de que o comportamento estratégico organizacional determina o estilo operacional de uma empresa, e adicionalmente, pode impactar de maneira simultânea nas decisões que envolvem a contabilidade.

Além disso, o estudo oferece evidências de que a diferenciação e agressividade do comportamento estratégico organizacional das empresas pode ser transformada em ação aos outros departamentos organizacionais, neste caso, em escolhas contábeis oportunistas (Miles et al., 1978; Olson et al., 2005; Malone et al., 2008). Na prática, se oferece uma visão de que os investidores e acionistas precisam avaliar o comportamento estratégico organizacional do negócio para não serem surpreendidos com a decadência e perda de valor da investida (Cole, 2001). Assim, a observação do comportamento estratégico de maneira isolada torna-se frágil, sendo necessário considerar que as ações estratégicas são transformadas em atitudes comportamentais dos gestores no reporte da informação contábil.

\section{REFERENCIAL TEÓRICO}

\subsection{Estratégias Organizacionais de Miles E Snow}

A estratégia organizacional corresponde a um conjunto de ações que visam o alcance do desempenho organizacional, por meio de crescimento sustentável, atração e satisfação de clientes (Thompson Jr. et al., 2008). Barney e Hesterly (2007, p. 5) comentam que a estratégia de uma empresa tem seu delineamento voltando à obtenção de vantagem competitiva frente aos fatores concorrenciais.

Do mesmo modo, Hitt, Ireland e Hoskisson (2008, p. 4) definem a estratégia como “[...] um conjunto integrado e coordenado de compromissos e ações para explorar competências essenciais e obter vantagem competitiva". Nesse sentido, a estratégia organizacional fornece um mapa de orientações utilizadas para combater a concorrência em mercados competitivos, apresentando diferenciais para geração de vantagem competitiva (Hitt et al., 2008).

No intuito de delinear os padrões de comportamento estratégico organizacional para descrever o processo de adaptação estrutural nas organizações, Miles et al. (1978) criaram tipologias estratégicas para o enquadramento das organizações. Esses autores definem que as organizações, de acordo com características estruturais do plano estratégico, tático e operacional, podem se enquadrar em quatro diferentes tipologias estratégicas: defensor, prospector, analisador e reativo.

Dessa forma, a empresa enquadrada na estratégia defensor teria características de apropriação e domínio do mercado, com produção de um número limitado de produtos diferenciados para determinado segmento (Miles et al., 1978; Zahra \& Pearce, 1990). O defensor procura impedir a entrada de concorrentes, valendo-se da política de preços e com produtos de qualidade (Hughes \& Morgan, 2008).

Ao contrário do defensor, a capacidade principal do prospector é vinculada à exploração de novos produtos e oportunidades do mercado. O prospector tem comportamento criativo que propicia mudanças e gera incertezas, exigindo constante adaptação dos concorrentes (Miles et al., 1978). Pleshko e Nickerson (2008) reconhecem que o prospector abrange comportamento estratégico mais agressivo e criativo, dando ênfase à inovação de produtos e na atuação do mercado (Aragón-Sánchez \& Sánchez-Marín, 2005; Olson et al., 2005).

O comportamento prospector procura manter o ajuste entre o ambiente interno e externo e a flexibilidade organizacional (Morgan et al., 2003). Desse modo, a necessidade de constante aprendizado e flexibilidade se reflete no desenvolvimento de recursos estratégicos capazes de gerar agilidade, proatividade e agressividade (Slater \& Narver, 1993). O comportamento estratégico prospector difere do defensor, não apenas porque atende a um domínio de mercado mais amplo e dinâmico, mas pela flexibilidade nos processos internos, enquanto o defensor tem foco no monitoramento da eficiência interna (Kabanoff \& Brown, 2008).

Adicionalmente, Miles et al. (1978) e Porter (1980) sugerem que os comportamentos estratégicos de prospector e defensor podem ser distinguidos por duas abordagens rivais, respectivamente, denominadas de estratégias de diferenciação e de liderança em custo. A empresa com tipologia de prospector busca oferecer 
produtos que diferem dos concorrentes, adotando estratégia de diferenciação. Por outro lado, a empresa com tipologia de defensor busca oferecer produtos mais baratos, adotando estratégia de liderança em custo (Miles et al., 1978; Olson et al., 2005).

Já a empresa com comportamento estratégico de analisador procura minimizar os riscos, enquanto busca maximizar as oportunidades. A empresa com tipologia de analisador combina as forças estratégicas do prospector e do defensor, que em circunstâncias favoráveis de mercado apresenta agressividade, flexibilidade e criatividade (Miles et al., 1978; Olson et al., 2005; Malone et al., 2008). O analisador mantém uma posição segura e estável, mas ao mesmo tempo, movimenta-se de maneira agressiva no acompanhamento de novos desenvolvimentos da indústria (Pleshko \& Nickerson, 2008; Malone et al., 2008). Olson et al., (2005) comentam que o analisador está atento a novas ideias e aos diferenciais dos concorrentes.

Por fim, a organização com comportamento estratégico reativo exibe padrões inconsistentes e instáveis para ajustes no ambiente competitivo (Miles et al., 1978). O ciclo adaptativo da empresa com comportamento estratégico reativo consiste em responder de maneira inadequada às mudanças do ambiente competitivo, mostrando-se relutante para ações que exigem flexibilidade, agressividade e criatividade (Miles et al., 1978; Malone et al., 2008).

No comportamento reativo, a firma se insere em um estado de instabilidade, quase permanente, sendo típico de organizações que não apresentam nenhuma relação coerente entre estratégia e estrutura organizacional (Miles et al., 1978; Hoffmann et al., 2009). A ausência de uma orientação estratégica faz com que os reativos modifiquem suas ações somente quando recebem pressão do mercado (Somavilla et al., 2013).

De maneira geral, Miles et al. (1978) argumentam que o defensor e o prospector estão em lados opostos de um continuum de sistematização estratégica. Já o analisador apresenta certa agressividade no comportamento de diferenciação e inovação dos produtos e serviços, pela utilização de uma mescla estratégica que contempla características do prospector. Por outro lado, o reativo atua de maneira pacífica no processo competitivo, se mostrando relutante à ações agressivas de competição (Miles et al., 1978; Slater \& Narver, 1993; Aragón-Sánchez \& Sánchez-Marín, 2005; Olson et al., 2005; Malone et al., 2008; Pleshko \& Nickerson, 2008).

As diferentes tipologias estratégicas apresentadas por Miles et al. (1978) descrevem a maneira como as organizações se posicionam no mercado, sendo importante para os investidores na análise da sustentabilidade dos negócios. Dessa forma, o comportamento estratégico, demonstrado por meio do relatório de administração, torna-se fator relevante para que acionistas e investidores tenham uma compreensão do futuro organizacional (Cole, 2001).

Bentley et al. (2013) determinaram que as estratégias organizacionais contribuem para o tamanho e a complexidade da empresa e de seus processos de negócios e, portanto, podem refletir também nas demais escolhas da gestão, podendo assim, interferir nas escolhas contábeis oportunistas que prejudicam a qualidade da informação contábil. Dessa forma, a diferenciação encontrada na estratégia de negócios da empresa prospectora e analisadora pode ser transformada em ações agressivas na diferenciação das escolhas contábeis (Miles et al., 1978; Olson et al., 2005; Malone et al., 2008).

Hoffmann et al. (2009) mencionam que em empresas com comportamento estratégico analítico ou prospector, os gestores procuram minimizar os riscos e maximizar as oportunidades de lucro. As implicações dos incentivos advindos da competição sobre as decisões e escolhas contábeis que envolvem a discricionariedade dos executivos foram investigadas sob o prisma do gerenciamento.

Além disso, Hou e Robinson (2006) argumentam que o grau de competição afeta as estratégias que determinam as decisões operacionais e contábeis das organizações. Nesse sentido, Marciukaityte e Park (2009) identificaram que o ambiente competitivo reduz as práticas contábeis que distorcem a realidade econômica do negócio, inclusive aumentando o conteúdo informacional dos números contábeis. O ambiente competitivo foi considerado uma das maiores forças econômicas em direção à eficiência na redução da expropriação dos acionistas minoritários (Shleifer \& Vishny, 1997).

Ao considerar as ponderações teóricas de que os diferentes comportamentos estratégicos podem ser transformados em ações administrativas e de gestão, considera-se também que as atitudes de agressividade e criatividade são disseminadas no ambiente corporativo em escolhas contábeis oportunistas por meio das práticas de gerenciamento de resultados.

\subsection{Práticas Contábeis de Gerenciamento de Resultados Vinculadas ao Comportamento Estratégico Organizacional}

As alterações propositais, respeitando os limites legais, nos números contábeis fazem emergir o gerenciamento de resultados. As alterações nas escolhas contábeis são possíveis devido à discricionariedade e flexibilidade das normas contábeis (Martinez, 2001). O gerenciamento de resultados tem sido utilizado pelos gestores para modificar, intencionalmente, a informação contábil reportada e, consequentemente, mascarar o verdadeiro desempenho organizacional, no intuito de influenciar as relações contratuais (Paulo, 2007).

Healy e Wahlen (1999) esclarecem que o uso difundido da informação contábil pelos investidores e 
analistas de mercado pode criar incentivos para escolhas contábeis oportunistas, na tentativa de gerenciar os resultados e interferir no desempenho organizacional reportado. Portanto, o gerenciamento de resultados tem sua predição pautada nas escolhas de políticas contábeis pelos gestores, no intuito de alcançar objetivos específicos (Scott, 2006).

Parte da literatura sobre qualidade da informação contábil considera que a governança corporativa pode restringir práticas de gerenciamento de resultados. Tais estudos concentraram esforços em observar o monitoramento organizacional, analisando o efeito dos mecanismos internos e externos de governança corporativa sobre a restrição e/ou mitigação das práticas de gerenciamento de resultados (Jaggi, 1975; Jensen, 1993; Saudagaran \& Diga, 1997; Eisenberg, Sundgren \& Wells, 1998; Wei, Wang \& Zhang, 2013).

Zahra, Priem e Rasheed (2005) argumentam que os fatores de interferência na eficiência dos mecanismos de monitoramento têm sido pouco explorados nos estudos em contabilidade. A evidência de que o comportamento estratégico do negócio pode ser disseminado para todo o ambiente organizacional faz emergir a necessidade de se explorar a interferência do comportamento estratégico do negócio sobre a eficiência dos mecanismos de governança corporativa no monitoramento das escolhas contábeis oportunistas (Miles et al., 1978).

Além disso, as informações contábeis podem ser afetadas, parcialmente, pela política contábil adotada pela gestão, que inclui considerações sobre a concorrência e estratégia empresarial. Sob essa premissa, a prática de gerenciamento de resultados também pode emergir das estratégias de negócio utilizadas pela organização para combater a concorrência (Healy \& Palepu, 2012; Andayani \& Warsono, 2013).

Diante das evidências, observou-se que o efeito do comportamento estratégico organizacional sobre o gerenciamento de resultados não tem sido explorado nos países em desenvolvimento. Por outro lado, estudos em países desenvolvidos focalizaram na prática de gerenciamento de resultados mediante atividades reais, dando ênfase à interferência das estratégias do negócio sobre as modificações intencionais nos aspectos operacionais da empresa (Andayani \& Warsono, 2013; Wu et al., 2015).

De maneira complementar, alguns estudos analisaram a influência do ambiente competitivo sobre as práticas de gerenciamento de resultados (Almeida, Faria, Costa \& Brandão, 2009; Marciukaityte \& Park, 2009; Karuna \& Subramanyam, 2012; Markarian \& Santalo, 2014), contudo, apontaram resultados inconsistentes. Almeida et al. (2009) avaliaram o efeito dos grupos estratégicos, obtidos pelos diferentes setores da indústria, nas práticas de gerenciamento de resultados. Os resultados indicam práticas diferenciadas de gerenciamento de resultados pelo modelo de Jones Modificado (1995) em sete grupos estratégicos, e em nove grupos estratégicos pelo modelo KS (1995). Os resultados indicam práticas heterogêneas de gerenciamento de resultados contábeis entre companhias de um mesmo setor, sugerindo-se a análise por meio de grupos estratégicos.

Marciukaityte e Park (2009) demonstraram que a concorrência do produto no mercado reduz os problemas de agência, restringindo o gerenciamento de resultados. Os achados indicam que as empresas de indústrias mais competitivas são menos propensas a se envolverem em gerenciamento de resultados mediante escolhas contábeis. Adicionalmente, concluíram que as empresas em indústrias competitivas apresentam menores divergências sobre as previsões dos analistas. De maneira geral, sugerem que a existência de maior consistência com a previsão dos analistas e menor distorção nos lucros reportados reduzem a assimetria de informação entre gestores e o mercado.

De maneira contrária, Karuna e Subramanyam (2012), ao estudarem o efeito da concorrência do produto no mercado sobre os incentivos para manipulação dos resultados, relataram que a manipulação dos resultados é compensadora em mercados competitivos, uma vez que a divulgação de bons resultados é fator preponderante para o mercado.

Do mesmo modo, Markarian e Santalo (2014) analisaram a relação entre a concorrência do produto no mercado, pela indústria, e as práticas de gerenciamento de resultados. Os autores concluíram que existe uma relação positiva entre a concorrência e as práticas de gerenciamento de resultados. Tais achados sugerem que os fatores da indústria desempenham papel vital na variação da extensão do gerenciamento de resultados entre as empresas, fornecendo evidências sobre os efeitos perversos da concorrência empresarial.

Diante dos achados, $\mathrm{Wu}$ et al. (2015) justificaram que as inconsistências nos estudos de competitividade e gerenciamento de resultados podem ser resultado da inobservância conjunta entre o ambiente competitivo e o comportamento estratégico organizacional com relação às práticas de gerenciamento de resultados. Tais evidências são confirmadas pelos estudos que focalizaram a relação entre o comportamento estratégico organizacional e a prática de gerenciamento de resultados e/ou qualidade da informação contábil.

Andayani e Warsono (2013) observaram a influência da empresa estratégica prospectoradefensiva e a especialização do auditor na indústria sobre o gerenciamento de resultados mediante atividades reais e na qualidade dos lucros. Os autores sugerem que a auditoria com especialização na indústria e a estratégia defensiva da empresa não podem restringir o gerenciamento de resultados, enquanto a estratégia prospectora da empresa pode restringir tal comportamento. 
Bentley et al. (2013) utilizaram as tipologias estratégicas de Miles et al. (1978) para examinar se as empresas que seguem diferentes estratégias de negócios estão expostas a ocorrência de comunicação de irregularidades financeiras, e se as estratégias de negócios das empresas são fatores determinantes do esforço da auditoria para atestar as informações financeiras reportadas pelas empresas. O estudo oferece evidências de que as empresas com tipologia de prospector são mais propensas a ocorrência de comunicação de irregularidades financeiras, em comparação com as empresas com tipologia de defensor. Ao examinar a relação entre a estratégia de negócios e o esforço de auditoria, fornecem evidências sobre o grau em que as firmas de auditoria parecem incorporar a estratégia de negócios no desenvolvimento de seu planejamento de auditoria.

Wu et al. (2015) exploraram as relações entre estratégias de negócios, concorrência e gerenciamento de resultados. Compuseram a amostra da pesquisa 2.037 empresas de capital aberto da China. Os achados sugerem que as empresas que seguem estratégia de liderança de custo são propensas a um nível mais elevado de gerenciamento de resultados mediante atividades reais. As empresas que seguem estratégia de diferenciação são menos propensas a utilizar tal prática.

Diante das evidências, a presente pesquisa contribui ao explorar o comportamento estratégico organizacional como fator determinante das escolhas contábeis oportunistas, que alavancam a prática de gerenciamento de resultados. Nessa perspectiva, as evidências apontadas nos estudos anteriores oferecem respaldo para sugerir que o comportamento estratégico agressivo no ambiente de negócios dissemina práticas homogêneas nas escolhas contábeis e, portanto, pode contribuir para práticas de gerenciamento de resultados.

\section{PROCEDIMENTOS METODOLÓGICOS}

Ao visar a consecução do objetivo geral do estudo, a pesquisa foi realizada por meio de análise documental para identificar as estratégias competitivas nos relatórios de administração e dos números apresentados nas demonstrações contábeis para o cálculo do gerenciamento de resultados das organizações em estudo.

A população da pesquisa foi composta pelas empresas do setor de bens industriais, consumo nãocíclico, e materiais básicos listadas na BM\&FBovespa.
A escolha desses setores ocorreu pela similaridade dos mercados. Portanto, tais empresas teriam as mesmas condições para o estabelecimento de suas estratégias, expurgando a possibilidade da ocorrência de interferência de determinadas estratégias estarem vinculadas às condições dos setores diferenciados.Caso os setores fossem heterogêneos, poderia se criar vieses nos resultados da pesquisa, visto que haveria possíveis diferenças na adoção ou predominância de determinadas estratégias. Assim, a amostra da pesquisa foi constituída por 78 empresas que apresentaram todas as informações necessárias para a identificação das estratégias e os dados financeiros.

Realizou-se a análise de conteúdo nos relatórios da administração do ano de 2013 a partir das inferências que determinaram as estratégias (prospectora, defensiva, analítica e/ou reativa), de acordo com a tipologia do Miles et al. (1978).

A análise nos relatórios de administração foi feita de acordo com o estudo recente de Pletsch et al. (2015), no qual, a título de exemplo, as inferências como "[...] o ano de 2013 iniciou-se diferente dos últimos anos vividos pela Companhia. Enquanto 2011 e 2012 foram anos marcados por grandes eventos como IPO, Follow-on, diversas aquisições e fechamentos de novas parcerias, 2013 foi um ano em que focamos na melhoria dos processos internos, buscando ganhos de eficiência que nos proporcionasse um contínuo crescimento orgânico. Entregamos resultados sólidos não só nas linhas de receita, como também na diluição dos custos e contenção do cancelamento e inadimplência, sem perder qualidade nos serviços" foram categorizadas como analisadora.

Já as inferências observadas como “[...] lançamos a Skol Beats Extreme e Brahma 0,0\%, que em pouco mais de seis meses já virou líder da categoria de cervejas não-alcoólicas; dentro da nossa estratégia de crescimento nas Regiões Norte e Nordeste, tivemos mais um ano de ganho de market share; e, na categoria de RefrigeNanc, aumentamos nossa participação de mercado" foram categorizadas como prospectora. Conforme mencionado no exemplo, seguiu-se esta análise para os 78 relatórios da administração das firmas.

Em seguida, as estratégias competitivas observadas, foram categorizadas, também em planilha eletrônica, com a finalidade da aplicação da análise multivariada de dados (ANOVA). A Tabela 1 mostra a categorização das estratégias competitivas de acordo com Miles et al. (1978). 
Comportamento Estratégico Organizacional e a Prática de Gerenciamento de Resultados nas Empresas Brasileiras

Tabela 1 - Categorização das estratégias competitivas de acordo com Miles et al. (1978)

\begin{tabular}{|l|c|}
\hline \multicolumn{1}{|c|}{ ESTRATÉGIAS } & CATEGORIZAÇ̃̃O \\
\hline Estratégia Defensiva & 1 \\
\hline Estratégia Prospectora & 2 \\
\hline Estratégia Analisadora & 3 \\
\hline Estratégia Reativa & 4 \\
\hline
\end{tabular}

Fonte: Dados da pesquisa.

As empresas identificadas com estratégia defensiva foram categorizadas em 1 , com estratégia prospectora foram categorizadas em 2 , com estratégia analítica foram categorizadas em 3 e as empresas com estratégia reativa foram categorizadas com 4 . Desta forma, a categorização determinou a variável independente da pesquisa (estratégias competitivas).

$\mathrm{Na}$ sequência, com os números apresentados nas demonstrações contábeis para o cálculo do gerenciamento de resultados, utilizou-se a regressão linear múltipla pelo modelo KS, conforme o Quadro 1, com o intuito de verificar o nível de gerenciamento de resultados das organizações e a análise multivariada ANOVA visando o tratamento dos dados. Contudo, destaca-se que se utilizou o modelo KS por ser o mesmo utilizado por investigações anteriores (Almeida et al., 2009; Marciukaityte \& Park, 2009; Karuna \& Subramanyam, 2012; Markarian \& Santalo, 2014).

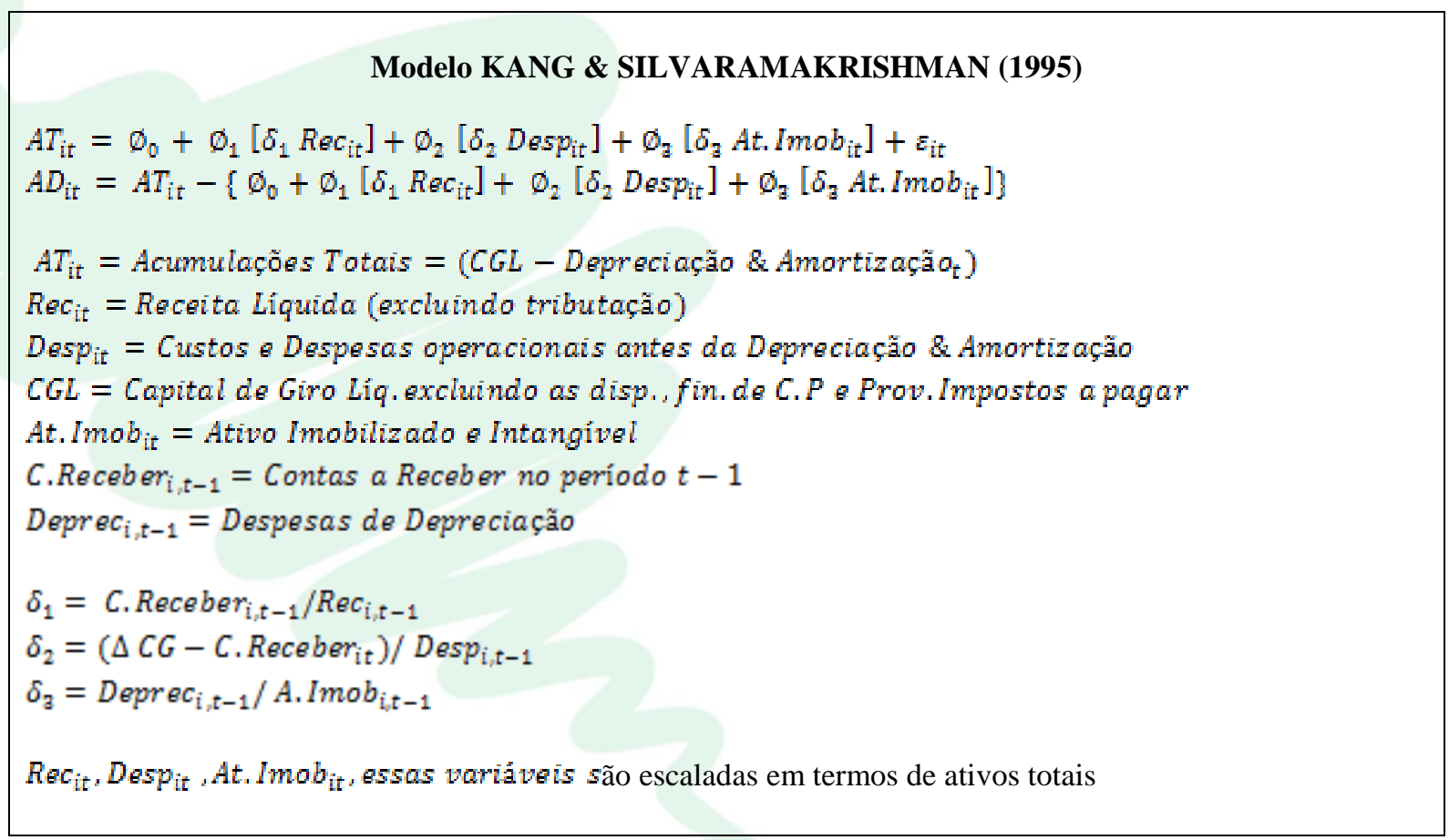

Quadro 1 - Modelo KS para identificar gerenciamento de resultados Fonte: Adaptado de Martinez (2008).

O modelo KS permite extrair as informações diretamente das contas do balanço patrimonial, para buscar explicar a dimensão dos Accruals Totais. A variável AT (Accruals Totais) é constituída pela variação do capital de giro líquido, sendo esse saldo escalonado pelos ativos totais (Martinez, 2008). A Rec é representada pela receita líquida excluída dos impostos sobre vendas, medida em termos de porcentagem dos ativos totais. A Desp é representada pelo total de despesas operacionais, incluindo CMV, CPV, Despesas de vendas e Despesas Administrativas, escalonadas pelos ativos totais (Martinez, 2008).
A variável A.Imob é representada pelo valor do Ativo Permanente, escalonada pelos ativos totais. Os parâmetros $\boldsymbol{\delta} \mathbf{1}, \boldsymbol{\delta} \mathbf{2}$ e $\mathbf{\delta 3}$ podem ser interpretados como os indicadores de rotatividade que procuram acomodar fatores específicos e compensam o fato do modelo KS estimar a amostra conjunta de várias empresas (cross-

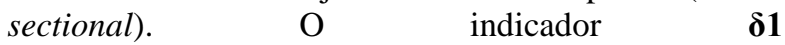
$\left[\delta_{1}=C\right.$. Receber $\left._{i, t-1} / \operatorname{Rec}_{i, t-1}\right]$ representa a razão entre contas a receber e receitas do ano anterior, multiplicada pelas vendas do período $\left[\delta_{1} x \operatorname{Rec}_{i t}\right]$. $\mathrm{O}$ indicador 


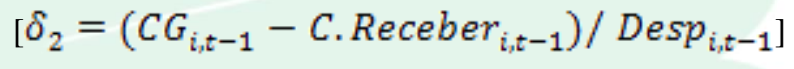

representa a razão entre o capital de giro líquido e as despesas operacionais do período anterior, multiplicada pelas despesas operacionais do período $\left[\delta_{2} x\right.$ Desp $\left._{i t}\right] . \quad$ Por $\quad$ fim, $\quad$ o $\quad \boldsymbol{\delta 3}$ $\left[\delta_{3}=\right.$ Deprec $_{i, t-1} /$ A. Imob $\left._{i, t-1}\right]$ constitui a razão entre as despesas de depreciação e os ativos imobilizados do período anterior, multiplicada pelo ativo imobilizado do período $\left[\delta_{3} x \mathrm{~A} \cdot \mathrm{Imo} b_{i t}\right]$ (MARTINEZ, 2008).
A partir disso, utilizou-se do teste de diferença de médias (ANOVA), com uso do software SPSS, para verificar se a média de accruals discricionários apresenta-se diferente de acordo com os diferentes comportamentos estratégicos organizacionais, conforme categorização exposta na Tabela 1. Além disso, foi adicionado ao teste a verificação da diferença de médias do tamanho da empresa e nível de endividamento geral com relação aos diferentes comportamentos estratégicos organizacionais.

Para dar robustez aos achados, foi adicionado um modelo complementar de regressão linear múltipla, conforme equação exposta no Quadro 2.

$$
G R=B_{1}+B_{2} C E A+B_{2} E N D+B_{4} T A M+\varepsilon_{i t}
$$

Em que:

GR = Gerenciamento de resultados medido pelos accruals discricionários do modelo KS no ano t;

CEA = Dummy igual 1 para as empresas com comportamento estratégico de agressividade (prospector e analisador), e 0 para as empresas com comportamento estratégico oposto (defensivo e reativo);

END = Endividamento no ano t;

$\mathrm{TAM}=\mathrm{LN}$ dos ativos totais no ano $\mathrm{t}$.

Quadro 2 - Modelo que verifica a influência do comportamento estratégico agressivo sobre práticas oportunistas de gerenciamento de resultados

Fonte: Dados da pesquisa.

Destaca-se que a variável dependente do modelo foi estabelecida pelos accruals discricionários do modelo KS, com vista a verificar se comportamentos estratégicos de agressividade, flexibilidade, proatividade e criatividade interferem nas práticas de gerenciamento de resultados.

Para tanto, a variável explicativa foi estabelecida pela dummy igual 1 para as empresas com comportamento estratégico de agressividade, proatividade, flexibilidade e criatividade, que conforme a literatura são característicos de empresas com tipologia de prospector e ou analisador (Miles et al., 1978; Morgan et al., 2003; Olson et al., 2005; AragónSánchez \& Sánchez-Marín, 2005). Já a dummy igual a 0 foi categorizada para as empresas com comportamento estratégico pacífico e relutantes a alterações e mudanças de inovação, que conforme a literatura são características de empresas com tipologia de defensor e reativo (Miles et al., 1978; Malone et al., 2008).
Além disso, foram adicionadas variáveis de controle que são amplamente reconhecidas como fatores explicativos do nível de gerenciamento de resultados nas empresas, ou seja, o tamanho das organizações e seu respectivo endividamento geral. Foi utilizado o software SPSS para obter os achados do modelo de regressão linear múltipla ante exposto.

\section{ANÁLISE DOS RESULTADOS}

Primeiramente, a título ilustrativo, são apresentadas algumas observações que determinaram a categorização das empresas em suas respectivas tipologias estratégicas (defensora, prospectora, analisadora e reativa).

No Quadro 3 são destacadas algumas observações que determinaram a categorização das empresas pela tipologia defensora. 


\begin{tabular}{|c|c|c|}
\hline EMPRESA & OBSERVAÇÃO & SUSTENTAÇÃO TEÓRICA \\
\hline Empresa 1 & $\begin{array}{l}\text { [...] foi um ano em que focamos na melhoria } \\
\text { dos processos internos, buscando ganhos de } \\
\text { eficiência que nos proporcionassem um } \\
\text { contínuo crescimento orgânico. Entregamos os } \\
\text { resultados, como também na diluição dos } \\
\text { custos e contenção do cancelamento e } \\
\text { inadimplência, sem perder qualidade" }\end{array}$ & $\begin{array}{l}\text { O defensor busca manter um ambiente } \\
\text { estável, produzindo apenas um conjunto de } \\
\text { produtos direcionados a um segmento } \\
\text { estreito do mercado, e acima de tudo, } \\
\text { buscando a eficiência nos processos. }\end{array}$ \\
\hline Empresa 2 & $\begin{array}{l}\text { "[...] em sete décadas de atuação solidificou-se } \\
\text { uma reputação de qualidade e excelência na } \\
\text { fabricação de aços planos, bem como na } \\
\text { estratégia de constante aumento na } \\
\text { produtividade e eficiência" }\end{array}$ & $\begin{array}{l}\text { A tipologia defensora é caracterizada pela } \\
\text { constante eficiência na produtividade do } \\
\text { portfólio de produtos já existentes. Além } \\
\text { disso, possui alta imagem e qualidade em } \\
\text { seus produtos. }\end{array}$ \\
\hline
\end{tabular}

Quadro 3 - Observações para categorização da tipologia defensora segundo Miles et al. (1978) Fonte: Dados da pesquisa.

As firmas que adotam a estratégia defensora focam na melhoria do seu processo produtivo atual, buscando eficiência na produção dos produtos, sem a busca constante pela inovação e lançamento de novos produtos. Destacam-se, no Quadro 4, algumas observações que determinaram a categorização das empresas pela tipologia estratégica prospectora.

\begin{tabular}{|c|c|c|}
\hline EMPRESA & OBSERVAÇÃO & SUSTENTAÇÃO TEÓRICA \\
\hline Empresa 3 & $\begin{array}{l}\text { "[...] lançamos dois produtos, que em pouco mais de } \\
\text { seis meses viraram líder da categoria de cervejas não } \\
\text { alcoólicas; dentro da nossa estratégia de crescimento } \\
\text { nas Regiões Norte e Nordeste, tivemos mais ano de } \\
\text { ganho de Market Share; e, na categoria de } \\
\text { RefrigeNanc, aumentamos a participação de } \\
\text { mercado." }\end{array}$ & $\begin{array}{l}\text { O prospector está envolvido em um } \\
\text { ambiente mais dinâmico, em busca de } \\
\text { inovação, novos produtos e } \\
\text { oportunidades de mercado. }\end{array}$ \\
\hline Empresa 4 & $\begin{array}{l}\text { "[...] buscando acelerar e reforçar a capacidade de } \\
\text { inovação e aumento da cadeia produtiva de álcoois, a } \\
\text { área de pesquisa, desenvolvimento e inovação } \\
\text { formalizou acordos com empresas de tecnologia } \\
\text { internacionais destinadas a desenvolver processos, } \\
\text { equipamentos e produtos capazes de agregar valor às } \\
\text { linhas atuais da Elekeiroz." }\end{array}$ & 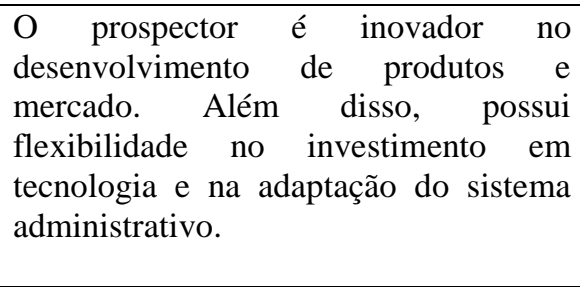 \\
\hline
\end{tabular}

Quadro 4 - Observações para categorização da tipologia prospectora segundo Miles et al. (1978) Fonte: Dados da pesquisa.

Verifica-se que as empresas caracterizadas pela estratégia prospectora estão focadas no constante lançamento de novos produtos, na inovação e no crescimento de mercado. Além disso, apresentam flexibilidade, proatividade e criatividade na inovação dos produtos e processos.

$\mathrm{Na}$ sequência, o Quadro 5 demonstra algumas observações que determinaram a categorização pela tipologia estratégica analisadora. 
Comportamento Estratégico Organizacional e a Prática de Gerenciamento de Resultados nas Empresas

Brasileiras

\begin{tabular}{|c|c|c|}
\hline EMPRESA & OBSERVAÇÃO & SUSTENTAÇÃO TEÓRICA \\
\hline Empresa 5 & $\begin{array}{l}\text { "[...]a Companhia ao longo de } 2013 \text { selecionou cerca } \\
\text { de } 250 \text { projetos que obedecem a critérios rígidos de: } \\
\text { aumento de volume de alunos; melhoria de margens; } \\
\text { melhoria de qualidade acadêmica e de serviços; e } \\
\text { retorno sobre o investimento. Entre os principais } \\
\text { projetos, a Companhia destaca: ensino a distância } \\
\text { com um encontro presencial por semana, cursos de } \\
\text { Graduação } 100 \% \text { online, novos polos de Cursos } \\
\text { Livres, Cursos Preparatórios Online, lançamento de } \\
\text { novos cursos de graduação, expansão de campi e } \\
\text { treinamento do corpo docente." }\end{array}$ & $\begin{array}{l}\text { O analítico é uma combinação dos } \\
\text { tipos prospector e defensor. O analítico } \\
\text { tenta minimizar o risco e maximizar a } \\
\text { oportunidade de lucro, ou seja, } \\
\text { combina, em um único sistema, os } \\
\text { pontos fortes do prospector e do } \\
\text { defensor. Assim, a palavra que melhor } \\
\text { descreve a abordagem adaptativa do } \\
\text { Analítico é "equilíbrio". }\end{array}$ \\
\hline Empresa 6 & $\begin{array}{l}\text { "[...] o ano de } 2013 \text { foi marcado pela conclusão de } \\
\text { um importante ciclo de crescimento experimentado } \\
\text { nos anos anteriores, em razão da consolidação e } \\
\text { expansão da marca, pela aquisição dos negócios } \\
\text { adquiridos em 2011. Estes movimentos permitiram à } \\
\text { empresa ampliar sua atuação nos mercados regionais, } \\
\text { expandir sua oferta de serviços e crescer seu market- } \\
\text { share em públicos pertencentes a diversos } \\
\text { segmentos." }\end{array}$ & $\begin{array}{l}\text { O analítico diferencia a estrutura e os } \\
\text { processos da organização para } \\
\text { acomodar áreas estáveis e dinâmicas de } \\
\text { funcionamento. Assim, o analítico } \\
\text { combina esforços de aspectos do } \\
\text { defensor (consolidação de mercado } \\
\text { com eficiência) e do prospector } \\
\text { (ampliação de serviços e oferta em } \\
\text { novos mercados). }\end{array}$ \\
\hline
\end{tabular}

Quadro 5 - Observação para categorização da tipologia analisadora segundo Miles et al. (1978)

Fonte: Dados da pesquisa.

Observa-se que as empresas com características de estratégia analisadora estão focadas na melhoria dos processos e eficiência de seus produtos, no entanto, também estão preocupadas com a constante inovação, pelo lançamento de novos produtos e crescimento perante o mercado. Posteriormente, o Quadro 6 mostra algumas observações que determinaram a categorização das empresas pela tipologia estratégica reativa.

\begin{tabular}{|c|c|c|}
\hline EMPRESA & OBSERVAÇÃO & SUSTENTAÇÃO TEÓRICA \\
\hline Empresa 7 & $\begin{array}{l}\text { "[...] em decorrência de um cenário menos } \\
\text { favorável, mostrou capacidade e agilidade } \\
\text { para adequar sua estratégia de acordo com os } \\
\text { rumos do mercado e registrou um } \\
\text { desempenho expressivo, com ganhos de } \\
\text { Market-share } \\
\text { diferentes negócios." }\end{array}$ & $\begin{array}{l}\text { O reativo exibe um padrão de } \\
\text { ajuste ao seu ambiente que é } \\
\text { inconsistente e instável; este tipo } \\
\text { carece de um conjunto de } \\
\text { mecanismos que são postos em } \\
\text { prática quando confrontados com } \\
\text { um ambiente em mudança. }\end{array}$ \\
\hline Empresa 8 & $\begin{array}{l}\text { "[...] com o objetivo de mitigar o ambiente } \\
\text { de preços baixos, a companhia implementou } \\
\text { uma estratégia de hedge bem sucedida a } \\
\text { partir de uma inteligência de mercado } \\
\text { diferenciada." }\end{array}$ & $\begin{array}{l}\text { O reativo existe em um estado de } \\
\text { instabilidade quase permanente. O } \\
\text { ciclo "adaptativo" do reator } \\
\text { consiste em responder à mudança } \\
\text { ambiental e de incerteza, com um } \\
\text { mau desempenho, e em seguida, } \\
\text { ser relutante em agir } \\
\text { agressivamente no futuro. }\end{array}$ \\
\hline
\end{tabular}

Quadro 6 - Observação para a categorização da tipologia reativa segundo Miles et al. (1978) Fonte: Dados da pesquisa.

Verifica-se que as organizações com características da estratégia reativa estão preocupadas em reagir perante às imposições e externalidades do mercado. A ocorrência de aspectos do ambiente externo faz com que estas organizações tomem decisões estratégicas para melhorar seu desempenho perante a ocorrência do fato. Portanto, a reação estratégica das empresas com comportamento reativo 
ocorre somente quando o mercado sinaliza um fato extraordinário.

Observa-se que os relatórios de administração divulgados pelas organizações estudadas corroboram Cole (2001) e demonstram, mesmo que de maneira implícita, o comportamento estratégico organizacional, corroborando a compreensão de administradores, acionistas e investidores sobre o futuro organizacional, como também possibilitam a vinculação dos fatores estratégicos a outros aspectos organizacionais, conforme esboçado no decorrer da análise deste estudo.
Contudo, há uma limitação na análise elaborada para definição dos perfis de comportamento estratégico, por não terem sido entrevistados gestores e colaboradores das empresas, o que tornaria inexequível para a elaboração de um estudo quantitativo, fato que justificativa a opção de observar apenas os relatórios de administração das empresas.

$\mathrm{Na}$ Tabela 2 apresenta-se um resumo com a frequência das estratégias competitivas de Miles e Snow, observadas nas empresas que compõem a amostra.

Tabela 2 - Frequência das estratégias competitivas de Miles e Snow

\begin{tabular}{|l|c|c|c|c|c|c|c|c|}
\hline \multirow{2}{*}{ Estratégias } & \multicolumn{2}{|c|}{ Bens Industriais } & \multicolumn{2}{c|}{$\begin{array}{c}\text { Consumo Não- } \\
\text { Cíclico }\end{array}$} & Materiais Básicos & \multicolumn{2}{c|}{ Total } \\
\cline { 2 - 9 } & Quant. & $\mathbf{\%}$ & Quant. & $\mathbf{\%}$ & Quant. & \% & Quant. & $\%$ \\
\hline Defensora & 3 & 12,00 & 9 & 31,03 & 7 & 29,17 & 19 & 24,36 \\
\hline Prospectora & 13 & 52,00 & 14 & 48,28 & 4 & 16,67 & 31 & 39,74 \\
\hline Analisadora & 3 & 12,00 & 3 & 10,34 & 7 & 29,17 & 13 & 16,67 \\
\hline Reativa & 6 & 24,00 & 3 & 10,34 & 6 & 25,00 & 15 & 19,23 \\
\hline \multicolumn{1}{|c|}{ Total } & $\mathbf{2 5}$ & $\mathbf{3 2 , 0 5}$ & $\mathbf{2 9}$ & $\mathbf{3 7 , 1 7}$ & $\mathbf{2 4}$ & $\mathbf{3 0 , 7 7}$ & $\mathbf{7 8}$ & $\mathbf{1 0 0 , 0 0}$ \\
\hline
\end{tabular}

Fonte: Dados da pesquisa.

Na Tabela 2 é demonstrado que a maior parte das empresas $(39,7 \%)$ foram identificadas na tipologia estratégica prospectora. $\mathrm{O}$ menor número de empresas $(16,7 \%)$ foi identificado pela tipologia estratégia analisadora. Em relação aos setores, o de bens industriais e consumo não-cíclico apresentam predominância para a tipologia estratégica prospectora, respectivamente com $52 \%$ e $48 \%$. Por outro lado, no setor de materiais básicos predominou as estratégias defensora e analisadora, ambas com 29,2\%.

$\mathrm{Na}$ Tabela 3 apresenta-se a estatística descritiva das variáveis segregadas por setor das empresas da amostra.

Tabela 3 - Estatística Descritiva das variáveis segregadas por setor

\begin{tabular}{|c|l|c|c|c|c|}
\hline \multirow{2}{*}{ Setor } & \multicolumn{1}{|c|}{ Variáveis } & Média & $\begin{array}{c}\text { Desvio- } \\
\text { Padrão }\end{array}$ & Mínimo & Máximo \\
\hline \multirow{2}{*}{$\begin{array}{c}\text { Bens } \\
\text { Industriais }\end{array}$} & Gerenciamento de Resultados & $-0,103$ & 0,320 & $-1,900$ & 0,507 \\
\cline { 2 - 6 } & Tamanho & 2.554 .826 & 2.779 .442 & 16.187 & 23.760 .310 \\
\cline { 2 - 6 } & Endividamento & 79,17 & 29,19 & 39,36 & 259,87 \\
\hline \multirow{2}{*}{$\begin{array}{c}\text { Consumo } \\
\text { Não-Cíclico }\end{array}$} & Gerenciamento de Resultados & 0,048 & 0,0566 & $-0,264$ & 0,172 \\
\cline { 2 - 6 } & Tamanho & 14.556 .788 & 13.443 .466 & 135.299 & 68.674 .019 \\
\cline { 2 - 6 } & Endividamento & 59,28 & 15,39 & 27,41 & 117,43 \\
\hline \multirow{2}{*}{$\begin{array}{c}\text { Materiais } \\
\text { Básicos }\end{array}$} & Gerenciamento de Resultados & 0,047 & 0,137 & $-0,872$ & 0,370 \\
\cline { 2 - 6 } & Tamanho & 24.814 .210 & 30.879 .990 & 73.833 & 291.880 .311 \\
\cline { 2 - 6 } & Endividamento & 63,29 & 23,35 & 11,84 & 182,63 \\
\hline
\end{tabular}

Fonte: Dados da pesquisa.

Verifica-se na Tabela 3 que, em média, as empresas do setor de bens industriais possuem práticas para o gerenciamento de resultados negativos $(-0,103)$. As empresas do setor de consumo não cíclico e materiais básicos possuem, em média, um nível de gerenciamento de resultados muito próximo, respectivamente com 0,048 e 0,047 . Em relação ao tamanho medido pelo ativo total, observa-se que as empresas do setor de bens industriais são, em média, significativamente menores do que as empresas dos setores de consumo não cíclico e materiais básicos. Por fim, em relação ao endividamento, é possível relatar que, em média, as empresas do setor de bens industriais são as mais endividadas, com um índice de endividamento geral de 79,17\%.

A Tabela 4 mostra a estatística descritiva das variáveis segregadas de acordo com seus respectivos comportamentos estratégicos. 
Comportamento Estratégico Organizacional e a Prática de Gerenciamento de Resultados nas Empresas Brasileiras

Tabela 4 - Estatística descritiva das variáveis segregadas por estratégia

\begin{tabular}{|c|l|c|c|c|c|}
\hline Estratégias & \multicolumn{1}{|c|}{ Variáveis } & Média & $\begin{array}{c}\text { Desvio- } \\
\text { Padrão }\end{array}$ & Mínimo & Máximo \\
\hline \multirow{3}{*}{ Defensora } & Gerenciamento de Resultados & 0,010 & 0,0983 & $-0,518$ & 0,152 \\
\cline { 2 - 6 } & Tamanho & 26.418 .086 & 31.680 .228 & 73.833 & 291.880 .311 \\
\cline { 2 - 6 } & Endividamento & 60,72 & 16,81 & 36,88 & 144,49 \\
\hline \multirow{3}{*}{ Prospectora } & Gerenciamento de Resultados & 0,072 & 0,105 & $-0,602$ & 0,506 \\
\cline { 2 - 6 } & Tamanho & 13.703 .857 & 15.373 .666 & 124.593 & 68.674 .019 \\
\cline { 2 - 6 } & Endividamento & 58,86 & 15,57 & 27,41 & 104,44 \\
\hline \multirow{3}{*}{ Analisadora } & Gerenciamento de Resultados & 0,084 & 0,102 & $-0,264$ & 0,256 \\
\cline { 2 - 6 } & Tamanho & 4.365 .020 & 3.345 .862 & 100.167 & 14.919 .496 \\
\cline { 2 - 6 } & Endividamento & 77,55 & 24,35 & 46,63 & 182,64 \\
\hline \multirow{3}{*}{ Reativa } & Gerenciamento de Resultados & $-0,238$ & 0,422 & $-1,900$ & 0,370 \\
\cline { 2 - 6 } & Tamanho & 5.743 .164 & 7.191 .268 & 16.187 & 38.008 .352 \\
\cline { 2 - 6 } & Endividamento & 80,99 & 39,85 & 11,84 & 259,87 \\
\hline
\end{tabular}

Fonte: Dados da pesquisa.

Observa-se na Tabela 4 que, em média, as empresas com estratégias defensora gerenciam em menor proporção os resultados contábeis, com média de 0,010 para os accruals discricionários. Além disso, as empresas com estratégia prospectora e analisadora apresentam maior nível de gerenciamento de resultados visando aumentar os lucros, enquanto as empresas com estratégia reativa apresentam efeito inverso, ou seja, o maior nível de gerenciamento de resultados com o objetivo de reduzir os lucros $(-0,238)$. Em relação ao tamanho, verifica-se que em média as empresas com estratégia analisadora e reativa são as menores, enquanto as empresas com estratégia defensora são as maiores.

Por fim, em relação ao endividamento, é possível constatar que as empresas mais endividadas são as que possuem estratégia reativa, com índice de $80,99 \%$. O resultado corrobora com o estilo comportamental do reativo, em que as ações estratégicas de reação, para combater a concorrência e emergir em novos mercados, são efetividades apenas quando há acontecimentos significativos e, portanto, podem não estar preparadas para eventuais crises, fazendo com que dependam, em maior proporção que as demais empresas, de recursos de terceiros para enfrentar tais períodos.

Para verificar se existe associação entre a variável estratégias competitivas e a variável gerenciamento de resultados, além das variáveis de controle tamanho ( $\mathrm{LN}$ do ativo total) e endividamento foi aplicado o teste ANOVA. Por meio do teste verificou-se a existência de diferenças de médias estatisticamente significantes entre o nível de gerenciamento de resultados e as estratégias competitivas.

O resultado do Teste ANOVA é apresentado na Tabela 5.

Tabela 5 - Resultado do Teste ANOVA

\begin{tabular}{|c|l|c|c|c|c|c|}
\hline \multicolumn{2}{|c|}{} & $\begin{array}{c}\text { Soma dos } \\
\text { Quadrados }\end{array}$ & Df & Quadrado Médio & Z & Sig. \\
\hline \multirow{2}{*}{$\begin{array}{c}\text { Gerenciamento } \\
\text { de Resultados }\end{array}$} & Entre Grupos & 1,103 & 3 & 0,368 & 4,061 & $0,01^{*}$ \\
\cline { 2 - 7 } & Nos grupos & 6,698 & 74 & 0,091 & & \\
\hline \multirow{2}{*}{$\begin{array}{c}\text { Tamanho } \\
\text { (LN Ativo total) }\end{array}$} & Total & 7,801 & 77 & & & \\
\cline { 2 - 8 } & Nntre Grupos & 12,243 & 3 & 4,081 & 1,080 & 0,36 \\
\hline \multirow{3}{*}{ Endividamento grupos } & 279,615 & 74 & 3,779 & & \\
\cline { 2 - 8 } & Total & 291,857 & 77 & & & \\
\cline { 2 - 8 } & Nos Grupos & 6944,190 & 3 & 2314,730 & 1,927 & 0,13 \\
\cline { 2 - 7 } & Total & 95872,583 & 74 & 1200,981 & & \\
\hline
\end{tabular}

*Significância ao nível de 5\%

Fonte: Dados da pesquisa. 
Comportamento Estratégico Organizacional e a Prática de Gerenciamento de Resultados nas Empresas Brasileiras

Os resultados demonstrados na Tabela 5 evidenciam diferenças significativas, ao nível de 5\%, na intensidade do gerenciamento de resultados entre empresas com comportamento estratégico diferenciado. Por outro lado, o tamanho e o endividamento, não demonstraram diferentes em relação aos comportamentos estratégicos organizacionais.

$\mathrm{Na}$ sequência, foi elaborado o teste de tukey para comparações múltiplas do resultado apresentado na ANOVA (Tabela 5). As empresas foram categorizadas conforme sua tipologia estratégica, sendo: 1 para empresas com estratégia defensora, 2 para estratégia prospectora, 3 para estratégia analisadora e o 4 para estratégia reativa.

A Tabela 6 mostra o resultado do teste de tukey para comparações múltiplas na média de gerenciamento de resultados, tamanho e endividamento das empresas, em relação aos diferentes comportamentos estratégicos organizacionais.

Tabela 6 - Teste de tukey para comparações múltiplas

\begin{tabular}{|c|c|c|c|c|c|c|}
\hline \multirow{3}{*}{\multicolumn{3}{|c|}{ Variáveis }} & \multirow{4}{*}{$\begin{array}{c}\begin{array}{c}\text { Diferença média (I- } \\
\mathbf{J})\end{array} \\
-0,062\end{array}$} & \multirow{4}{*}{$\begin{array}{l}\text { Sig. } \\
0,893\end{array}$} & \multirow{2}{*}{\multicolumn{2}{|c|}{ Intervalo de Confiança $95 \%$}} \\
\hline & & & & & & \\
\hline \multirow{13}{*}{$\begin{array}{l}\text { Gerenciamento } \\
\text { de Resultados }\end{array}$} & \multirow{4}{*}{1,0} & & & & \multirow{2}{*}{$\begin{array}{c}\text { Limite inferior } \\
-0,292\end{array}$} & \multirow{2}{*}{$\begin{array}{c}\text { Limite superior } \\
0,168\end{array}$} \\
\hline & & 2,0 & & & & \\
\hline & & 3,0 & $-0,074$ & 0,903 & $-0,358$ & 0,210 \\
\hline & & 4,0 & 0,247 & $0,089^{*}$ & $-0,025$ & 0,520 \\
\hline & \multirow{3}{*}{2,0} & 1,0 & 0,062 & 0,893 & $-0,168$ & 0,292 \\
\hline & & 3,0 & $-0,011$ & 0,999 & $-0,273$ & 0,249 \\
\hline & & 4,0 & 0,309 & $0,009^{*}$ & 0,061 & 0,558 \\
\hline & \multirow{3}{*}{3,0} & 1,0 & 0,074 & 0,903 & $-0,210$ & 0,358 \\
\hline & & 2,0 & 0,011 & 0,999 & $-0,249$ & 0,273 \\
\hline & & 4,0 & 0,321 & $0,031^{*}$ & 0,022 & 0,621 \\
\hline & \multirow{3}{*}{4,0} & 1,0 & $-0,247$ & $0,089^{*}$ & $-0,520$ & 0,025 \\
\hline & & 2,0 & $-0,309$ & $0,009^{*}$ & $-0,558$ & $-0,061$ \\
\hline & & 3,0 & $-0,321$ & $0,031^{*}$ & $-0,621$ & $-0,022$ \\
\hline \multirow{12}{*}{ Tamanho } & \multirow{3}{*}{1,0} & 2,0 & 0,131 & 0,996 & $-1,357$ & 1,619 \\
\hline & & 3,0 & 0,570 & 0,847 & $-1,268$ & 2,409 \\
\hline & & 4,0 & 1,071 & 0,388 & $-0,693$ & 2,835 \\
\hline & \multirow{3}{*}{2,0} & 1,0 & $-0,131$ & 0,996 & $-1,619$ & 1,357 \\
\hline & & 3,0 & 0,439 & 0,903 & $-1,249$ & 2,127 \\
\hline & & 4,0 & 0,939 & 0,421 &,- 666 & 2,546 \\
\hline & \multirow{3}{*}{3,0} & 1,0 & $-0,570$ & 0,847 & $-2,409$ & 1,268 \\
\hline & & 2,0 & $-0,439$ & 0,903 & $-2,127$ & 1,249 \\
\hline & & 4,0 & 0,500 & 0,904 & $-1,435$ & 2,436 \\
\hline & \multirow{3}{*}{4,0} & 1,0 & $-1,071$ & 0,388 & $-2,835$ & 0,693 \\
\hline & & 2,0 & $-0,939$ & 0,421 & $-2,546$ & 0,666 \\
\hline & & 3,0 & $-0,500$ & 0,904 & $-2,436$ & 1,435 \\
\hline \multirow{12}{*}{ Endividamento } & \multirow{3}{*}{1,0} & 2,0 & 1,370 & 0,999 & $-25,168$ & 27,909 \\
\hline & & 3,0 & $-16,826$ & 0,535 & $-49,611$ & 15,959 \\
\hline & & 4,0 & $-20,269$ & 0,334 & $-51,730$ & 11,191 \\
\hline & \multirow{3}{*}{2,0} & 1,0 & $-1,370$ & 0,999 & $-27,909$ & 25,168 \\
\hline & & 3,0 & $-18,196$ & 0,391 & $-48,294$ & 11,900 \\
\hline & & 4,0 & $-21,640$ & 0,203 & $-50,289$ & 7,008 \\
\hline & \multirow{3}{*}{3,0} & 1,0 & 16,826 & 0,535 & $-15,959$ & 49,611 \\
\hline & & 2,0 & 18,196 & 0,391 & $-11,900$ & 48,294 \\
\hline & & 4,0 & $-3,443$ & 0,994 & $-37,959$ & 31,072 \\
\hline & \multirow{3}{*}{4,0} & 1,0 & 20,269 & 0,334 & $-11,191$ & 51,730 \\
\hline & & 2,0 & 21,640 & 0,203 & $-7,008$ & 50,289 \\
\hline & & 3,0 & 3,443 & 0,994 & $-31,072$ & 37,959 \\
\hline
\end{tabular}

Fonte: Dados da pesquisa.

Os resultados observados na Tabela 6 sugerem que o gerenciamento de resultados apresenta diferentes níveis entre empresas que adotam determinadas posturas de comportamento estratégico organizacional, corroborando com Hoffmann et al. (2009) e Bentley et al. (2013), os quais descreveram que as estratégias 
contribuem para a complexidade dos processos intraorganizacionais e refletem nas escolhas da gestão sobre aspectos de contabilidade, podendo ser prejudicial para a qualidade da informação contábil. De maneira específica, os achados sugerem que as empresas que adotam estratégia reativa (4) praticam o gerenciamento de resultados para reduzir os lucros em comparação às empresas com estratégia prospectora (2), analisadora (3), e defensora (1).

Os resultados revelam que as empresas com estratégia prospectora e analisadora, caracterizadas pelo comportamento estratégico de flexibilidade, proatividade, agressividade e criatividade, disseminam atitudes similares nas escolhas contábeis, visando o gerenciamento de resultados no intuito de reportar melhores resultados. Os achados corroboram Bentley et al. (2013), para os quais empresas com tipologia estratégica prospectora são mais propensas a distorções nas informações contábeis reportadas ao mercado de capitas, evidenciando menor qualidade da informação contábil. Conclui-se também que a diferenciação estratégica das empresas prospectora e analisadora pode se transformar em ações de agressividade na diferenciação das escolhas de contabilidade, corroborando Miles et al. (1978), Olson et al. (2005) e Malone et al. (2008).

Aceita-se o pressuposto de comportamento criativo do prospector e analisador, já reconhecido na questão da inovação de produtos e do mercado, e a partir dos achados desta pesquisa, adiciona-se a criatividade em inovação também refletida no prisma de resultados mais atrativos aos interesses organizacionais, corroborando Aragón-Sánchez e Sánchez-Marín (2005), Olson et al. (2005) e Pleshko e Neckerson (2008). Além disso, a flexibilidade dos processos internos operacionais do prospector e analisador também se reflete no uso das escolhas contábeis que oferecem maior flexibilidade para o resultado contábil desejado, corroborando Slater e Narver (1993), Morgan et al. (2003) e Kabanoff e Brown (2008).

Os resultados estão alinhados também com os achados de Hoffmann et al. (2009), em que as empresas com comportamento estratégico analítico ou prospector procuram minimizar os riscos e maximizar as oportunidades de lucro, que podem ser obtidas com o uso de práticas de gerenciamento de resultados. Além disso, os comportamentos estratégicos prospector e analisador estão atrelados ao melhor desempenho organizacional que pode ter sido obtido pela prática de gerenciamento de resultados (Thompson Jr. et al., 2008).

Por outro lado, o oposto ocorre com as empresas que adotam estratégia reativa, em que foi encontrado maior nível de gerenciamento de resultados com efeito para redução dos lucros. Assim, sugere-se que o monitoramento dos processos internos das empresas com comportamento estratégico defensor tem sido refletido na minimização das atitudes oportunistas, restringindo as práticas de gerenciamento de resultados e melhorando a qualidade da informação contábil em comparação com empresas que possuem outros comportamentos estratégicos, corroborando as exposições de Kabanoff e Brown (2008), em que os defensores seriam mais rígidos nos processos de controles internos.

Em relação às variáveis de controle, é possível inferir que, quanto ao tamanho, não foram encontradas diferenças estatisticamente significantes ao nível de 5\% de empresas com diferentes tipologias estratégicas, contrariando as evidências de Cadez e Guilding (2008), que demonstraram potencial relacionamento entre $o$ comportamento estratégico e o tamanho das organizações, resultado não encontrado nesta pesquisa. $\mathrm{O}$ mesmo resultado foi encontrado em relação ao endividamento, em que não foi possível inferir que empresas com diferentes tipologias estratégicas possuem diferentes níveis de endividamento.

Por fim, como teste de robustez adicional criou-se uma categorização para as estratégias de agressividade e as opostas, conforme defino na metodologia da pesquisa. Os achados estão apresentados na Tabela 7, a qual apresenta a influência do comportamento estratégico agressivo sobre a prática de gerenciamento de resultados.

Tabela 7 - Influência do comportamento estratégico agressivo sobre a prática de gerenciamento de resultados

\begin{tabular}{|l|c|c|}
\hline \multicolumn{1}{|c|}{ Variáveis independentes } & Coeficiente B & Significância \\
\hline (Constante) & 0,134 & 0,500 \\
\hline Endividamento & $-0,007$ & $0,000^{*}$ \\
\hline Tamanho & 0,015 & 0,213 \\
\hline Comportamento Estratégico de Agressividade & 0,140 & $0,002^{*}$ \\
\hline $\mathrm{R}^{2}$ Modelo & & 0,643 \\
\hline $\mathrm{R}^{2}$ Ajustado & 0,628 \\
\hline Significância do Modelo & $0,000^{*}$ \\
\hline
\end{tabular}

* Significância ao nível de 5\%

Fonte: Dados da pesquisa. 
Preliminarmente, destaca-se que foram atendidos os pressupostos da regressão linear múltipla. Desse modo, foi observado que não há multicolinearidade nos dados pelo VIF, que se mostrou menor do que 1,00. Além disso, os resíduos apresentaram dispersão homogênea com o teste de homoscedasticidade. Por fim, pelo teste de DurbinWatson, foi possível confirmar que não há auto correlação entre os resíduos do modelo.

Verifica-se na Tabela 7 que o comportamento estratégico organizacional de diferenciação e inovação (tipologia prospectora e/ou analisadora) transfere a agressividade e criatividade do ambiente competitivo para atitudes oportunistas de gerenciamento de resultados mediante escolhas contábeis. De maneira geral, o modelo indica que as variáveis endividamento, tamanho e comportamento estratégico de agressividade, em conjunto, exercem poder explicativo de $64,30 \%\left(\mathrm{R}^{2}\right)$ sobre a variabilidade na prática de gerenciamento de resultados.

Esse resultado contribui com a literatura do gerenciamento de resultados, apontando que empresas com comportamento estratégico de diferenciação nos produtos e que não primam pela liderança em custos são mais propensas a práticas agressivas de contabilidade. Conclui-se que a qualidade da informação contábil pode ser prejudicada pelo comportamento estratégico agressivo, caracterizado pela tipologia prospectora/analisadora.

Os achados contrariam as evidências de Andayani e Warsono (2013) e Wu et al. (2015), sobre a afirmação de que organizações com liderança em custo teriam propensão para práticas de gerenciamento de resultados. A diferença é que esses autores testaram essa relação com o GR mediante atividades operacionais, enquanto neste estudo se utilizou o GR por escolhas contábeis. Por outro lado, empresas com estratégias de diferenciação teriam tendência contrária, de minimizar tais práticas.

Sugere-se que a contradição nos achados pode ter ocorrido porque as empresas com estratégia de liderança em custo (defensiva) são menos agressivas e primam pela manutenção da estabilidade organizacional, e utilizariam o gerenciamento mediante atividades reais ao invés das escolhas contábeis, pela maior dificuldade de descoberta pela auditoria. Desse modo, sugere-se que novos estudos sejam alinhados à buscar explicações para determinar se as estratégias competitivas podem provocar diferentes ações de gerenciamento de resultados em função dos nível operacionais e de escolhas contábeis.

De maneira geral, confirma-se os lados opostos da sistematização estratégica entre os defensores/reativos e os prospectores/analisadores, adicionando um continuum que adentra aos demais processos internos de gestão informacional, corroborando Miles et al. (1978), Slater e Narver (1993), Aragón-Sánchez e Sánchez-Marín (2005),
Olson et al. (2005), Malone et al. (2008) e Pleshko e Nickerson (2008).

\section{CONSIDERAÇÕES FINAIS}

O objetivo do estudo foi verificar o efeito dos diferentes comportamentos estratégicos organizacionais sobre o comportamento oportunista dos gestores em práticas de gerenciamento de resultados mediante escolhas contábeis.

Com os resultados, foi possível inferir que, em média, as empresas com estratégias defensora gerenciam em menor proporção os resultados contábeis. As empresas com estratégias prospectora e analisadora apresentam maior propensão para o gerenciamento dos resultados com vista à obtenção de maiores lucros, enquanto as empresas com estratégia reativa apresentam maior nível de gerenciamento de resultados com a finalidade de reduzir os lucros.

Conclui-se que as empresas com comportamento estratégico de proatividade, agressividade, flexibilidade e criatividade, caracterizado nas empresas com tipologia de prospector e/ou analisador, tendem a apresentar o mesmo comportamento em relação às práticas de gerenciamento de resultados. Por outro lado, empresas com estratégia mais cautelosa, ou seja, defensora, gerenciam em menor proporção os resultados, ou tendem a gerenciar os resultados de forma a obter o alisamento dos lucros, estando preocupadas com a manutenção dos lucros.

$\mathrm{Na}$ prossecução da vantagem competitiva, muitas organizações têm procurado implementar processos de fabricação e funções administrativas que apoiem suas prioridades estratégicas específicas. Dessa forma, os achados contribuem ao adicionar que o comportamento estratégico agressivo implementado nos processos e funções administrativas também tem reflexo sobre as decisões que envolvem escolhas de contabilidade, apoiando as prioridades estratégicas de competitividade organizacional.

Conclui-se que a informação contábil normatizada é afetada pelas políticas de gestão que incluem considerações sobre as estratégias utilizadas para combater a concorrência, corroborando os estudos de Healy e Palepu (2012) e Andayani e Warsono (2013). Esta pesquisa contribui na visão de avaliação organizacional, por parte de administradores, acionistas e reguladores, que devem considerar os fatores estratégicos como antecedentes da qualidade da informação contábil divulgada pelas organizações.

Os resultados sugerem que os mecanismos de governança corporativa precisam dar maior ênfase sobre o monitoramento das atitudes oportunistas da gestão em empresas com comportamento estratégico prospector e analisador. A atuação mais efetiva dos mecanismos de monitoramento pode restringir práticas 
de gerenciamento de resultados e, portanto, minimizar futuros problemas de agência advindos do comportamento estratégico agressivo das organizações, corroborando os resultados de Zahra et al. (2005).

Conclui-se ainda que os achados estendem a literatura de qualidade da informação contábil, oferecendo evidências de que o comportamento estratégico organizacional deve ser explorado como determinante subjacente em métricas adicionais de qualidade da informação contábil. Os resultados indicam que as ações estratégicas são transferidas para atitudes comportamentais dos gestores nas escolhas contábeis, impactando na qualidade da informação contábil reportada. Assim, quando os stakeholders considerarem o comportamento estratégico antecedente da informação contábil divulgada pelas organizações, poderá haver uma redução dos conflitos de agência.

Adicionalmente, o financiamento externo tem sido considerado motivador e intensificador das práticas oportunistas de gerenciamento de resultados (Dechow e Sloan, 1991; Defond e Jiambalvo, 1994) e as empresas com comportamento estratégico de diferenciação dos produtos necessitam de altos investimentos em capital externo, para manter a agressividade e flexibilidade competitiva. Sob essa perspectiva, sugere-se que os achados sobre a maior intensidade de práticas de gerenciamento de resultados pelas empresas com comportamento de agressividade podem ser influenciados pela necessidade de resultados satisfatórios com a finalidade de manutenção dos covenants.

Sugere-se para que sejam elaborados estudos futuros que avaliem os efeitos do comportamento estratégico organizacional na relação entre os mecanismos de governança corporativa e incentivos regulatórios e de mercado sobre práticas de gerenciamento de resultados. Além disso, torna-se interessante os estudos que observem a causa e efeito das estratégias organizacionais, adicionando as perspectivas de Porter (1980), sobre a relação entre os incentivos, mecanismos de governança corporativa e as práticas de gerenciamento de resultados, bem como a suavização dos resultados, o conservadorismo contábil e demais proxies da qualidade da informação contábil.

As limitações da pesquisa incluem a utilização de apenas duas variáveis de controle (tamanho e endividamento) para explicar os incentivos a práticas de gerenciamento de resultados. Além disso, o estudo apresenta a limitação envolto da análise documental utilizada para mensurar e categorizar o comportamento estratégico organizacional, fazendo-se necessário estudos futuros que mitiguem o viés característico de tal procedimento metodológico. Para tanto, pesquisas futuras que captem de maneira diferenciada $o$ comportamento estratégico organizacional poderiam corroborar os resultados deste estudo.

\section{REFERÊNCIAS}

Almeida, J. E. F. de, Faria, L. H. L., da Costa, F. M., \& Brandão, M. M. (2009). Earnings management no Brasil: grupos estratégicos como nova variável explanatória. Revista de Contabilidade e Organizações, 3(6), 81-95.

Andayani, W., \& Warsono, S. (2013). Prospectordefender strategy, auditor industry specialization, earnings management through real activities, and earnings quality. Journal of Indonesian Economy and Business, 28(1), 115.

Aragón-Sánchez, A., \& Sánchez-Marín, G. (2005). Strategic orientation, management characteristics, and performance: A study of Spanish SMEs. Journal of Small Business Management, 43(3), 287308.

Barney, J. B., \& Hesterly, W. S. (2007). Administração estratégica e vantagem competitiva. São Paulo: Pearson.

Bentley, K. A., Omer, T. C., \& Sharp, N. Y. (2013). Business strategy, financial reporting irregularities, and audit effort. Contemporary Accounting Research, 30(2), 780-817.

Burgelman, R. A., \& Grove, A. S. (2007). Let chaos reign, then rein in chaos-repeatedly: Managing strategic dynamics for corporate longevity. Strategic management journal, 28(10): 965-979.

Cadez, S., \& Guilding, C. (2008). An exploratory investigation of an integrated contingency model of strategic management accounting. Accounting, Organizations and Society, 33(7): 836-863.

Cole, C. J. (2001). Communicating key business strategies to investors. Journal of Corporate Accounting \& Finance, 13(1): 23-31.

Conant, J. S., Smart, D. T., \& Solano-Mendez, R. (1993). Generic retailing types, distinctive marketing competencies, and competitive advantage. Journal of retailing, 69(3): 254-279.

Dechow, P. M., \& Sloan, R. G. (1991). Executive incentives and the horizon problem: An empirical investigation. Journal of Accounting and Economics, 14(1), 51-89.

DeFond, M. L., \& Jiambalvo, J. (1994). Debt covenant violation and manipulation of accruals. Journal of Accounting and Economics, 17(1-2), 145-176.

Eisenberg, T., Sundgren, S., \& Wells, M. T. (1998). Larger board size and decreasing firm value in 
small firms. Journal of Financial Economics, 48(1): 35-54.

Gimenez, F. A. P., Pelisson, C., Kruger, E. G. S., \& Hayashi, JR. P. (1999). Estratégia em pequenas empresas: uma aplicação do modelo de Miles e Snow. Revista de administração contemporânea, 3(2): 53-74.

Healy, P. M., \& Wahlen, J. M. (1999). A review of the earnings management literature and its implications for standard setting. Accounting horizons, 13(4): 365-383.

Healy, P. M., \& Palepu, K. G. (2012). Business Analysis Valuation: Using Financial Statements. Cengage Learning.

Hitt, M. A., Ireland, R. D., \& Hoskisson, R. E. (2008). Administração estratégica: competitividade e globalização. 2. ed. São Paulo: Cengage Learning.

Hou, K., \& Robinson, D. T. (2006). Industry concentration and average stock returns. The Journal of Finance, 61(4): 1927-1956.

Hoffmann, R. A., Hoffmann, V. E., \& De Lorenzi Cance, E. L. P. (2009). As estratégias da microempresa varejista e seus estágios de informatização. Revista de Administração Mackenzie, 10(2).

Hughes, P., \& Morgan, R. E. (2008). Fitting strategic resources with product-market strategy: performance implications. Journal of Business Research, 61(4), 323-331.

Jaggi, B. L. (1975). The impact of the cultural environment on financial disclosures. International Journal of Accounting, 10(2): 75-84.

Johnson, H. T., \& Kaplan, R. S. (1987). Relevance lost. The rise and fall of management accounting, Boston.

Karuna, C., Subramanyam, K. R. \& Tian, F. (2012). Industry product market competition and earnings management. Working Paper, Disponível em: http://experiments.cob.calpoly.edu/seminars/karuna .pdf

Malone, K., Hales, B., Chan, J., Love, M., \& Rayner, J. (2008). Cloning an industry: Strategy typologies of Shanghai biotechnology companies. Journal of Commercial Biotechnology, 14(1), 31-42.

Marciukaityte, D., \& Park, J. C. (2009). Market competition and earnings management. Working
Paper, Disponível em:

http://ssrn.com/abstract_1361905

Martinez, A. L. (2008). Detectando earnings management no Brasil: estimando os accruals discricionários. Revista de Contabilidade e Finanças, USP, São Paulo, 19(46): 7-17.

Martinez, A. L. (2001). Gerenciamento dos resultados contábeis: estudo empírico das companhias abertas brasileiras. São Paulo, 2001. 153f. Tese (Doutorado em Ciências Contábeis) - Programa de PósGraduação em Ciências Contábeis, Departamentos de Contabilidade e Atuaria, Faculdade de Economia, Administração e Contabilidade da Universidade de São Paulo, São Paulo.

Markarian, G. \& Santalo, J. (2014). Product market competition, information and earnings management. Journal of Business Finance \& Accounting, 41(5/6): 572-599.

Miles, R. E., Snow, C. C., Meyer, A. D., \& Coleman, J. R. H. J. (1978). Organizational Strategy, Structure, and Process. The Academy of Management Review, 3(3): 546-562.

Morgan, R. E., Strong, C. A., \& McGuinness, T. (2003). Product-market positioning and prospector strategy: An analysis of strategic patterns from the resource-based perspective. European Journal of Marketing, 37(10), 1409-1439.

Olson, E. M., Slater, S. F., \& Hult, G. T. M. (2005). The importance of structure and process to strategy implementation. Business horizons, 48(1), 47-54.

Paulo, E. (2007). Manipulação das informações contábeis: uma análise teórica e empírica sobre os modelos operacionais de detecção de gerenciamento de resultados. 2007. Tese (Doutorado em Controladoria e Contabilidade) Universidade de São Paulo: São Paulo.

Pleshko, L., \& Nickerson, I. (2008). Strategic orientation, organizational structure, and the associated effects on performance in industrial firms. Academy of Strategic Management Journal, 7,95 .

Pletsch, C. S.; Dal Magro, C. B.; Silva, A. da; Lavarda, C. E. F. (2005). Estratégias competitivas e desempenho econômico-financeiro de empresas brasileiras. Revista de Contabilidade e Organizações, 9(25): 16-30.

Porter, M. E. (1980). Competitive strategy. New York: The Free Press. 
Rodrigues, J. J. M., \& António, N. J. D. S. (2010). Enraizamento e poder dos gestores. Revista Universo Contábil, 6(3): 129-139.

Saudagaran, S. M., \& Diga, J. G. (1997). Emerging capital markets: characteristics and policy Issues. Accounting Horizons, 11(2): 41-64.

Shank, J. K., \& Govindarajan, V. (1993). What drivers cost? a strategic cost management perspective. Advantages in Management Accounting, (2): 2746.

Shortell, S. M., \& Zajac, E. J. (1990). Perceptual and archival measures of Miles and Snow's strategic types: a comprehensive assessment of reliability and validity. Academy of Management Journal, 33(4): 817-832.

Shleifer, A., \& Vishny, R. (1997). A survey of corporate governance. Journal of Finance, 52(2): 737-783.

Slater, S. F., \& Narver, J. C. (1993). Product-market strategy and performance: an analysis of the Miles and Snow strategy types. European journal of marketing, 27(10): 33-51.

Somavilla, S. P., Machado, N. S., \& Sehnem, S. (2013). Comportamento Estratégico Segundo a Teoria de Miles e Snow: um Estudo de Caso em um Provedor de Internet do Norte do Rio Grande do
Sul. TPA-Teoria e Prática em Administração, 3(1):66-95.

Thompson, A. A., Strickland, A. J., \& Gamble, J. E. (2008). Administração estratégica. 15. ed. São Paulo: McGraw-Hill.

Wei, J., Wang, H., Fan, J., \& Zhang, Y. (2013). Corporate accidents, media coverage, and stock market responses: empirical study of the Chinese listed firms. Chinese Management Studies, 7(4): 617-630.

Wu, P., Gao, L., \& Gu, T. (2015). Business strategy, market competition and earnings management: Evidence from China. Chinese Management Studies, 9(3), 401-424.

Zahra, S. A., \& Pearce, J. A. (1990). Research evidence on the Miles-Snow typology. Journal of management, 16(4), 751-768.

Zahra, S. A., Priem, R. L., \& Rasheed, A. A. (2005). The antecedents and consequences of top

management fraud. Journal of Management, 31(6): 803-828.

Zajac, E. J., \& Shortell, S. M. (1989). Changing generic strategies: Likelihood, direction, and performance implications. Strategic Management Journal, 10(5): 413-430. 